\title{
Proposição de limiares críticos ambientais para uso em sistema de alertas de deslizamentos
}

\section{Proposal of environmental critical thresholds for use in landslides warnings system}

\author{
Rodolfo Moreda Mendes ${ }^{* 1} \bowtie(D)$, Mario Valerio Filho ${ }^{2} \bowtie\left(D\right.$, Jair Santoro ${ }^{3} \bowtie(D$, \\ Daniela Girio-Marchiori Faria ${ }^{3} \varangle\left(\mathbb{D}\right.$, Viviane Dias Alves Portela ${ }^{3} \bowtie$ (D)
}

${ }^{1}$ Centro Nacional de Monitoramento e Alertas de Desastres Naturais (Cemaden/MCTI) São José dos Campos, São Paulo, Brasil

Recebido (Received): 27/12/2019

2Universidade do Vale do Paraíba, São José dos Campos, São Paulo, Brasil

Aceito (Accepted):06/05/2020

3Instituto Geológico (IG/SMA), São Paulo, São Paulo, Brasil

E-mails: mvalerio@univap.br (MVF); jairsantor@yahoo.com.br (JS);

dgmfaria@gmail.com (DGMF); viviportela.85@gmail.com (VDAP)

*E-mail para correspondência: rmm.cemaden@gmail.com

Resumo: Sensores ambientais foram utilizados para monitorar encostas urbanas representativas de áreas de risco a deslizamentos em três municípios do estado de São Paulo (Ubatuba, Campos do Jordão e São José dos Campos), onde pluviômetros e sensores de umidade do solo foram instalados ao longo de perfis de alteração até 3,0 metros de profundidade. A leitura dos sensores foi realizada automaticamente em intervalos de 10 minutos; enquanto o envio automático dos dados via tecnologia GPRS/GSM (telefonia celular) foi feito em intervalos pré-programados de 4 horas. A ocorrência de vários deslizamentos nos três municípios durante o registro dos dados ambientais permitiu propor limiares críticos operacionais para serem usados em sistema de alerta de deslizamentos. Entre os parâmetros ambientais monitorados verificou-se que tanto a chuva (intensidade e acumulados de $24 \mathrm{~h}$ e $72 \mathrm{~h}$ ) como o teor de umidade do solo exercem papel fundamental na deflagração dos deslizamentos em encostas urbanas. A intensidade da chuva horária, chuva acumulada de 24 ou 72 horas e o aumento significativo do teor de umidade do solo até 3,0 metros de profundidade foram os principais parâmetros ambientais associados com as ocorrências dos deslizamentos registrados nas áreas estudadas. Outro aspecto relevante da pesquisa é a possibilidade de utilização dos limiares críticos em situações distintas nos sistemas de alerta a deslizamentos, ou seja, podem ser utilizados tanto para a entrada quanto para a saída de um determinado nível operacional utilizado no Plano Preventivo de Defesa Civil PPDC operado no Estado de São Paulo (“observação” para “atenção” e vice-versa, por exemplo).

Palavras-chaves: Monitoramento de campo; Sensores ambientais; Áreas de risco; PPDC.

Abstract: Environmental sensors were used to monitor urban slopes representative of landslide risk areas in three municipalities of the São Paulo State (Ubatuba, Campos do Jordão and São José dos Campos), where rainfall gauges and soil moisture sensors were installed along profiles up to 3.0 meters deep. The sensors were read automatically at 10 minute intervals; whereas automatic data transmission via GPRS / GSM (cellular) technology was done at pre-programmed intervals of 4 hours. The occurrence of several landslides in the three municipalities during the registration of environmental data allowed proposing critical operational thresholds to be used at landslide warning systems. Among the monitored environmental parameters, it was found that both rainfall (24h and $72 \mathrm{~h}$ accumulated intensity) and soil moisture content play a fundamental role in the triggering of landslides on urban slopes. The intensity of hourly rainfall, accumulated rainfall of 24 or 72 hours and the significant increase of soil moisture content up to 3.0 meters deep were the main environmental parameters associated with the occurrence of landslides recorded in the studied areas. Another relevant aspect of the research is the possibility of using the critical thresholds in different situations in landslide alert systems, that is, they can be used for entrance or return a certain operational level used by Preventive Civil Defense Plan - PPDC operated in the São Paulo State ("observation" for "attention" and vice-versa, for example). 


\section{Introdução}

A região sudeste do Brasil apresenta destaque no cenário nacional e mundial em questões de riscos geológicos devido, principalmente, ao elevado número de ocorrências de deslizamentos em encostas urbanas e ao número expressivo de municípios com áreas de risco a deslizamentos. Nesta situação, encontram-se alguns municípios localizados em regiões com elevada suscetibilidade à ocorrência de deslizamentos, particularmente aqueles municípios com áreas urbanas situadas nas encostas da Serra da Mantiqueira e Serra do Mar, conforme constatado atualmente pelo número significativo de ocorrências de deslizamentos registradas pelo Instituto Geológico do Estado de São Paulo, no âmbito do Plano Preventivo de Defesa Civil - PPDC (BROLLO; TOMINAGA, 2012).

No Estado de São Paulo, as atividades do Plano Preventivo de Defesa Civil - PPDC, específico para deslizamentos em encostas, iniciou-se após os acidentes em larga escala e com graves consequências que ocorreram no verão de 1987/1988. O objetivo principal do PPDC é evitar a ocorrência de mortes por meio da remoção preventiva das populações que ocupam áreas de risco, antes que os deslizamentos atinjam suas moradias. Para tal, essa ação do PPDC se baseia na previsão meteorológica, no monitoramento dos limiares críticos de chuva em cada município (chuva acumulada de 72 horas), e nas vistorias de campo para verificação de evidências de movimentação dos terrenos (trincas, degraus de abatimento, etc.). Os limiares críticos de chuva utilizados nas ações de remoção preventiva da população das áreas de risco foram definidos a partir do estudo de correlação entre chuvas e deslizamentos inicialmente concebida para o município de Cubatão, Estado de São Paulo (TATIZANA et al., 1987), conforme apresentado na Figura 1.

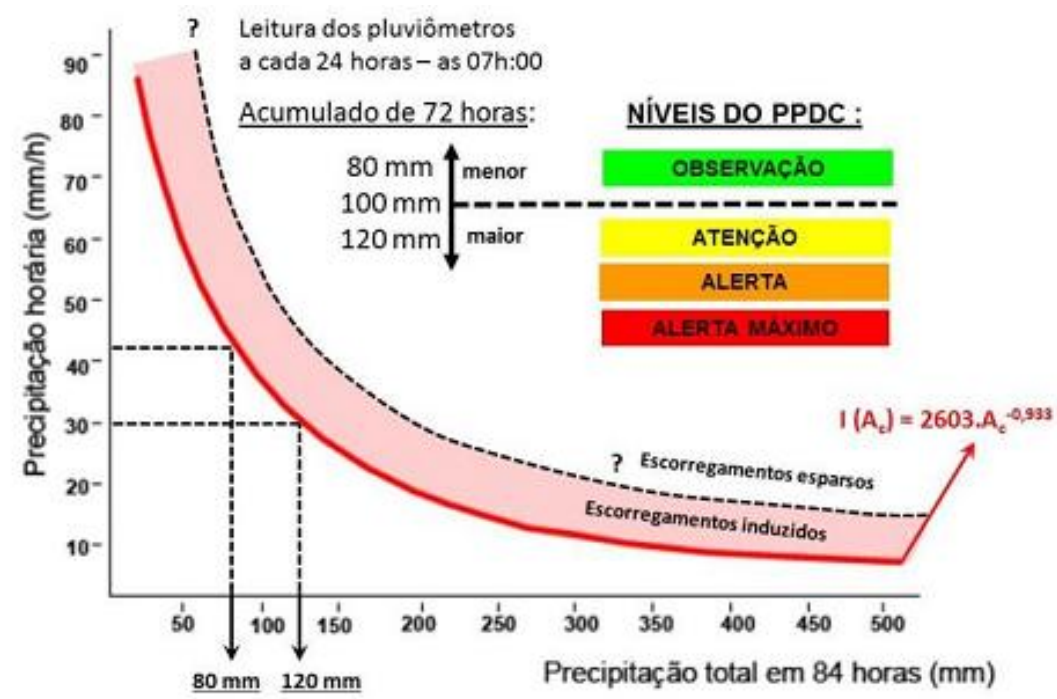

Figura 1: Limiares críticos de chuva e respectivos níveis operacionais do PPDC para deslizamentos em encostas no Estado de São Paulo (fonte: modificado de Tatizana et al., 1987).

Os resultados de correlação obtidos por Tatizana e colaboradores para o município de Cubatão foram posteriormente extrapolados para os demais municípios do Estado de São Paulo, tendo como referência os dados de chuva acumulada de 72 horas (Figura 1). Deste modo foram estabelecidos diferentes limiares críticos de chuva de 72 horas para os municípios operados pelo PPDC: região da Serra do Mar (Ubatuba) $120 \mathrm{~mm}$; região do Vale do Paraíba (São José dos Campos) - $100 \mathrm{~mm}$ e região da Serra da Mantiqueira (Campos do Jordão) - $80 \mathrm{~mm}$, conforme apresentado na Figura 1. Quando o valor da chuva acumulada de 72 horas ultrapassa os limiares críticos estabelecidos (80, 100 ou $120 \mathrm{~mm}$ - Figura 1), o nível operacional é alterado de "Observação" para "Atenção" e vistorias de campo são requeridas para avaliação dos terrenos. Caso sejam constatadas evidências de movimentação do terreno, o nível operacional é alterado para "Alerta" e ações de remoção preventiva da população de suas moradias são decretadas. O nível operacional "Alerta Máximo" é adotado apenas no caso de ocorrência de deslizamentos generalizados no município.

No entanto, observa-se que a distribuição espacial da chuva numa determinada região não é homogênea e tende a apresentar menor correlação quanto maior for a distância entre os pluviômetros representativos das 
áreas onde foram registrados os deslizamentos (FISCH et al., 2007). Logo, a extrapolação de dados pontuais de chuva representativa de uma determinada área, onde houve deslizamentos para representar limiares críticos de chuva em outras regiões, pode conter consideráveis incertezas para fins operacionais de PPDC.

Tem-se observado também que os limiares críticos de chuva utilizados em determinadas áreas podem não representar satisfatoriamente as situações críticas de chuva necessária para a deflagração de deslizamentos em outras regiões que apresentem características geológico-geotécnicas distintas, conforme constatado por Santoro et al. (2010). Além disso, o uso de medidores manuais de chuva não permite o acompanhamento "em tempo real" para emissão de alertas antecipados a qualquer hora do dia, pois as medições são feitas periodicamente a cada 24 horas.

A quantidade de chuva é o parâmetro ambiental mais utilizado para obtenção de limiares críticos para uso em sistemas de alerta antecipado, devido à sua notória relevância nos processos de preparação e deflagração dos deslizamentos. No entanto, quando usados isoladamente, os limiares de chuva (intensidade e acumulados) tendem a apresentar elevada incerteza, pois os processos de infiltração, retenção e drenagem da água da chuva nos perfis de solo e as consequentes alterações de umidade do solo nas encostas são complexos e não lineares. Portanto, a medição em tempo real da umidade do solo conjuntamente com os limiares de chuva permitirá prever de forma mais precisa o momento de ruptura de uma encosta (TOLL et al., 2010).

Os deslizamentos que ocorrem nas encostas brasileiras estão, na maioria dos casos, associados ao período chuvoso. Segundo Vargas (1999), a principal causa de ocorrência dos deslizamentos no Brasil é a redução da resistência do solo promovida pela infiltração de água das chuvas ao longo das camadas de solo não saturado. Essa constatação ressalta a necessidade do monitoramento em tempo real de variáveis do solo de cada região, com o objetivo de melhor entendimento do mecanismo de ruptura dos deslizamentos em áreas de risco, principalmente monitorar parâmetros ambientais complementares (tais como sucção matricial, temperatura e/ou umidade do solo) que permitam avaliar a forma de infiltração e retenção das águas de chuva.

Em outros países, as medições in situ do teor umidade do solo, juntamente com as medidas de precipitação em tempo real, tem sido frequentemente utilizadas com diferentes propósitos, por exemplo, de estudar o processo de infiltração superficial da chuva em encostas constituídas por solos saprolíticos (LI et al., 2005), investigar a influência da infiltração da chuva na instabilidade de encostas em solos não saturados (ZHAN et al., 2007), prever de forma mais confiável o momento de ruptura de uma encosta (TOLL et al., 2010), melhorar a compreensão do mecanismo deflagrador dos deslizamentos causados pela chuva em solos saprolíticos não saturados (LEUNG et al., 2011), obtenção de limiares críticos para avaliação do nível de segurança das encostas (PIRONE et al., 2015), utilização em sistemas de alertas antecipados a deslizamentos (CHÁVEZ et al., 2016).

Recentemente o monitoramento de encostas adquiriu grande importância para a comunidade científica, pois o uso de sensores de monitoramento adequados é uma ferramenta poderosa para a compreensão dos aspectos dinâmicos dos deslizamentos, permitindo sua correta análise e interpretação, sendo principalmente útil e essencial na identificação de situações de alerta. No caso da implementação de sistemas de monitoramento e alertas, a escolha adequada dos parâmetros ambientais (chuva, sucção matricial, temperatura e/ou umidade do solo) e seus respectivos limiares críticos é muito importante para evitar falsos alertas (ANGELI et al., 2000).

Neste contexto, o objetivo principal do trabalho é apresentar os resultados de um sistema de monitoramento de dois (02) parâmetros ambientais, constituído por sensores de chuva e umidade do solo; e instrumentos de aquisição e transmissão automática de dados, que foi implantado nos municípios de Campos do Jordão, São José dos Campos e Ubatuba, no Estado de São Paulo. A partir da análise das informações registradas pelos sensores durante a ocorrência de diversos deslizamentos nas áreas monitoradas são discutidas a adoção de limiares críticos operacionais e a implantação em sistemas de monitoramento de encostas urbanas, visando sua aplicação nos Planos Preventivos de Defesa Civil - PPDC para emissão de alertas.

\section{Materiais e método}

\subsection{Caracterização das áreas monitoradas}

Os critérios usados para a escolha das áreas de monitoramento levaram principalmente em consideração a existência de setores com grau de risco Alto (R3) ou Muito Alto (R4) a deslizamentos, conforme dados de mapeamentos de risco existentes (AHRENDT; ZUQUETTE, 2003; PMSJC, 2014; IG, 2014); e aspectos 
regionais do meio físico e urbano de cada município: i) variações climáticas regionais distintas (em termos de distribuição de chuvas), ii) aspectos regionais do relevo, iii) áreas com local seguro para instalação dos sensores e equipamentos de monitoramento e iv) áreas com bons sinais de telefonia celular para permitir a transmissão dos dados. Na Figura 2 são apresentados os municípios escolhidos para a instalação dos sensores de monitoramento in situ (chuva e teor de umidade do solo).
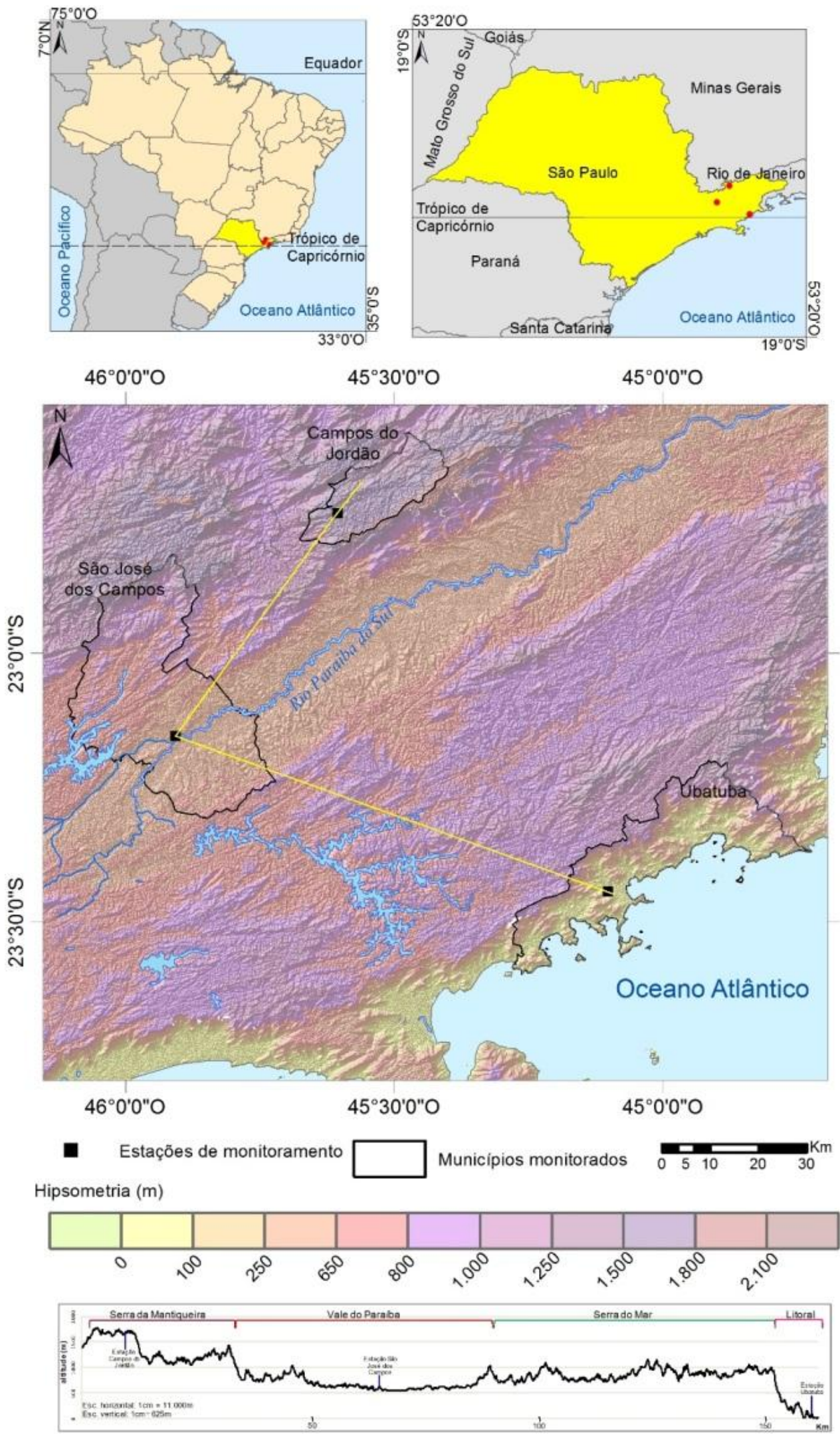

Figura 2: Localização dos municípios onde foram instalados os sensores de chuva e umidade do solo. 
A caracterização dos perfis de solo monitorados foi realizada inicialmente no campo observando-se os setores de risco considerados mais críticos (grau de risco R3 ou R4), representativos das áreas de risco a deslizamentos (linha amarela tracejada) dos municípios de Campos do Jordão, São José dos Campos e Ubatuba, conforme apresentado na Figura 3. Para isso, utilizaram-se os setores das áreas de risco a deslizamentos mapeadas por Ahrendt e Zuquette (2003), PMSJC (2014) e IG (2014). Com base na análise comparativa das fichas de campo das áreas de risco mapeadas por esses autores, constatou-se haver formas bem distintas de uso e ocupação, onde a área de risco de Campos do Jordão possui maior adensamento urbano e, consequentemente, maior quantidade de intervenções antrópicas (cortes, aterros, lançamentos de água servida, vazamentos em tubulações, etc.), seguida pelas áreas de São José dos Campos e Ubatuba.
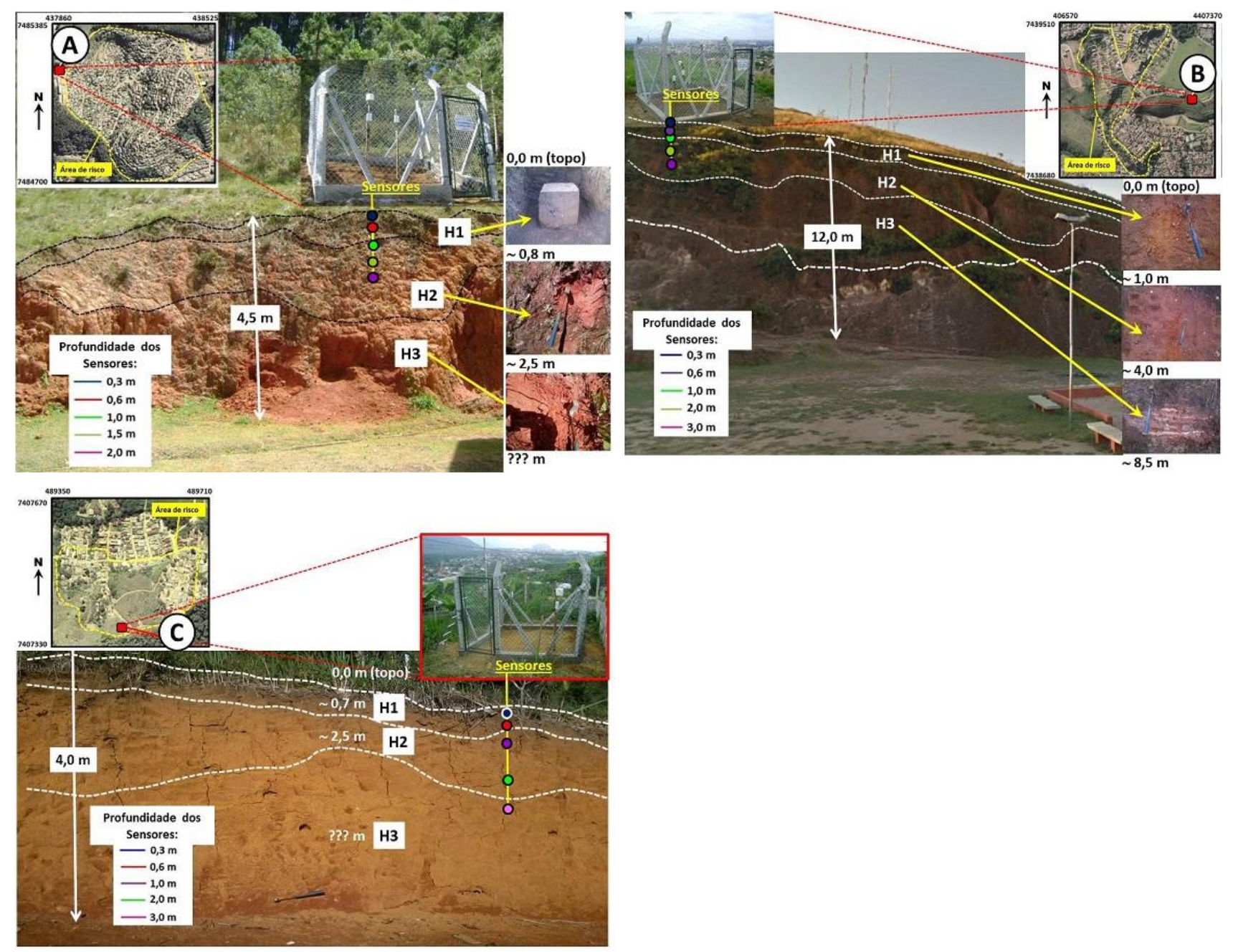

Figura 3: Áreas de risco monitoradas e detalhe da localização dos sensores de umidade instalados nos perfis de solo em Campos do Jordão (A), São José dos Campos (B) e Ubatuba (C).

Os perfis de solo representativos das áreas de risco monitoradas são formados pela seguinte sequência de camadas ou horizontes de solo: i) Horizonte "H1"- solo superficial com espessura da ordem de 0,7 a 1,0 metro; ii) Horizonte "H2" - solo de coloração relativamente homogênea com espessura da ordem de 2,5 a 4,0 metros e iii) Horizonte "H3" - solo de alteração da rocha com espessura variando de 5 a 15 metros (Figura 3). Ressalta-se que geralmente o nível de água é profundo nas encostas monitoradas, sendo que também não foram observados afloramentos ou surgências de água durante as investigações de campo.

A partir das amostras deformadas coletadas nas três (03) áreas de estudo foram realizados os seguintes ensaios de caracterização dos solos: analise granulométrica conjunta (NBR-7181/84), massa específica dos grãos de solo (NBR-6508/84), massa específica natural, limites de Atterberg (NBR-6459/84 e NBR7180/84). A partir das amostras indeformadas de solos coletadas nas áreas de estudo foram realizados também ensaios para obtenção das curvas de retenção de água (Figura 4). As curvas de retenção de água dos solos foram obtidas a partir da utilização da mesa de tensão (sucções entre 0,1 a $75 \mathrm{kPa}$ ) e extrator de membrana (sucções entre 100 a $1.500 \mathrm{kPa}$ ). As características gerais das áreas monitoradas envolvendo aspectos geológicos, geotécnicos, geomorfológicos e climáticos são apresentadas nas Tabelas 1 e 2 e na Figura 4. 

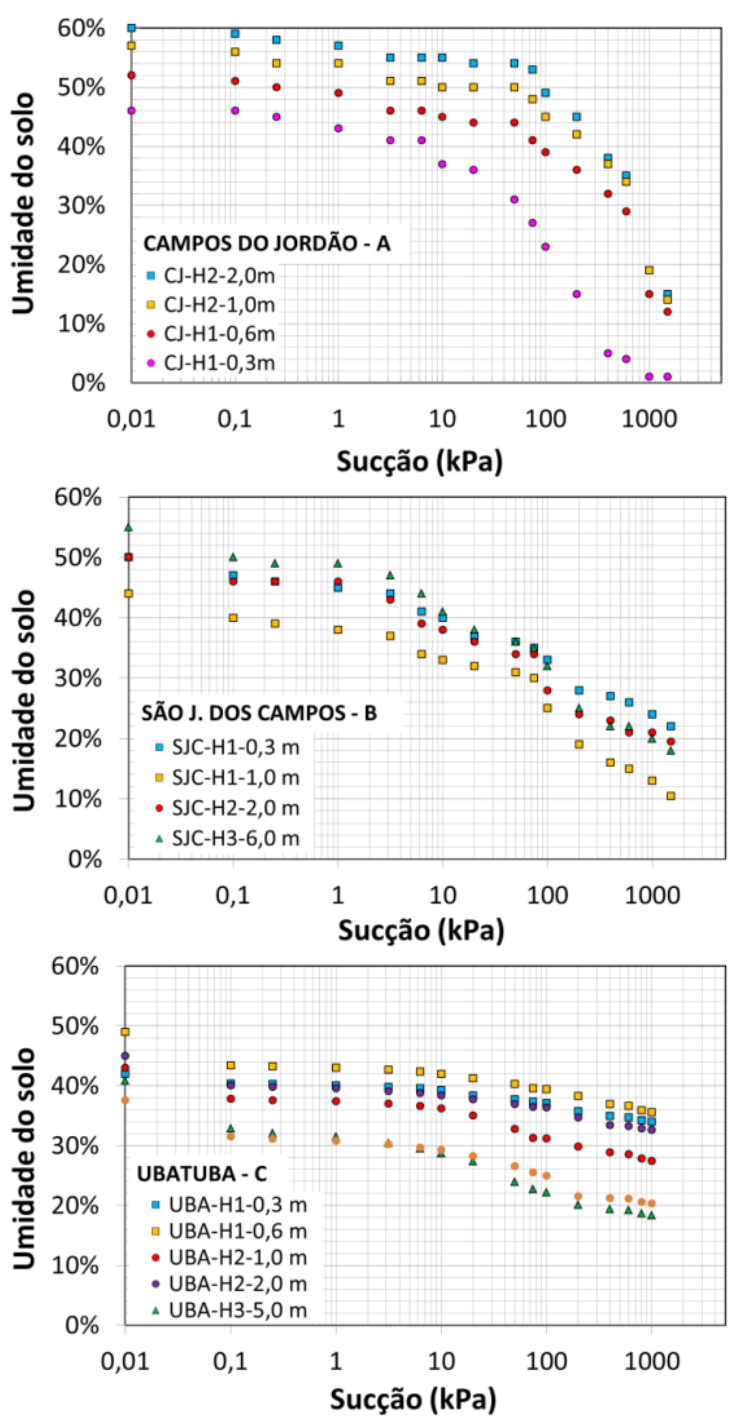

Figura 4: Curvas de retenção de água dos solos representativos das áreas estudadas - Campos do Jordão (A), São José dos Campos (B) e Ubatuba (C).

Tabela 1. Caracterização geológica, geomorfológica e climática das áreas monitoradas.

\begin{tabular}{|c|c|c|c|c|c|c|c|c|c|c|c|c|}
\hline & \multicolumn{6}{|c|}{ Características geológicas e geomorfológicas } & \multicolumn{6}{|c|}{ Características climáticas } \\
\hline & \multirow{2}{*}{$\begin{array}{l}\text { Altitu } \\
\text { de (m) }\end{array}$} & \multirow{2}{*}{$\begin{array}{c}\text { Decl. } \\
\left({ }^{\circ}\right)\end{array}$} & \multirow{2}{*}{$\begin{array}{l}\text { Forma } \\
\text { da } \\
\text { vert. }\end{array}$} & \multirow{2}{*}{$\begin{array}{l}\text { Set } \\
\text { or }\end{array}$} & \multirow{2}{*}{$\begin{array}{c}\text { Compart. do } \\
\text { relevo }\end{array}$} & \multirow{2}{*}{ Litol. } & \multirow{2}{*}{ Período } & \multicolumn{2}{|c|}{ Localização das estações } & \multicolumn{3}{|c|}{$\begin{array}{l}\text { Precipitação média } \\
\text { anual }(\mathrm{mm})\end{array}$} \\
\hline & & & & & & & & Latitude / Longitude & Altitude (m) & Mín. & $\begin{array}{l}\text { Má } \\
\text { x. }\end{array}$ & Méd. \\
\hline 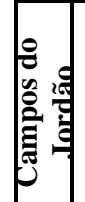 & 1710 & $\begin{array}{c}20 \mathrm{a} \\
30\end{array}$ & 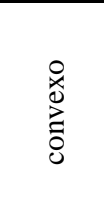 & ڤે & 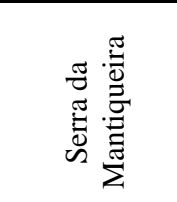 & 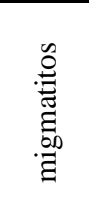 & $\begin{array}{l}1937 \mathrm{a} \\
2004 \\
\\
1973 \mathrm{a} \\
2001\end{array}$ & $\begin{array}{l}22^{\circ} 43^{\prime} \mathrm{S} / 45^{\circ} 34^{\prime} \mathrm{W} \\
22^{\circ} 42^{\prime} \mathrm{S} / 45^{\circ} 29^{\prime} \mathrm{W}\end{array}$ & $\begin{array}{l}1590 \\
1620\end{array}$ & $\begin{array}{l}1.035 \\
1.342\end{array}$ & $\begin{array}{l}4.4 \\
57 \\
\\
2.7 \\
86\end{array}$ & 1.801 \\
\hline 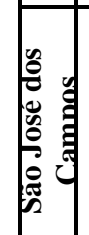 & 633 & $\begin{array}{l}2 \mathrm{a} \\
12\end{array}$ & 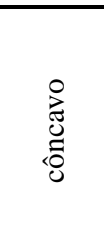 & ڤ̊․․ & 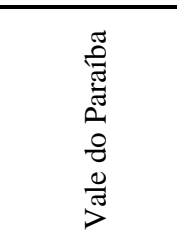 & 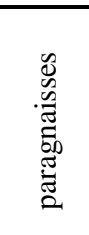 & $\begin{array}{c}1943 \mathrm{a} \\
2003 \\
\\
1943 \mathrm{a} \\
2000\end{array}$ & $\begin{array}{l}23^{\circ} 11^{\prime} \mathrm{S} / 45^{\circ} 53^{\prime} \mathrm{W} \\
23^{\circ} 03^{\prime} \mathrm{S} / 45^{\circ} 54^{\prime} \mathrm{W}\end{array}$ & 570 & 917 & $\begin{array}{l}2.0 \\
55 \\
\\
2.2 \\
71\end{array}$ & 1.289 \\
\hline 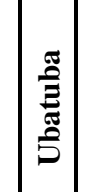 & 73 & $\begin{array}{c}12 \mathrm{a} \\
20\end{array}$ & 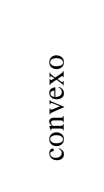 & 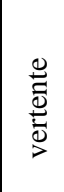 & 氶 & 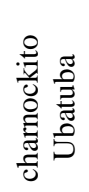 & $\begin{array}{l}1957 \mathrm{a} \\
2004 \\
\\
1945 \mathrm{a} \\
2000\end{array}$ & $\begin{array}{l}23^{\circ} 23^{\prime} \mathrm{S} / 45^{\circ} 07^{\prime} \mathrm{W} \\
23^{\circ} 23^{\prime} \mathrm{S} / 44^{\circ} 50^{\prime} \mathrm{W}\end{array}$ & 142 & $\begin{array}{l}1.777 \\
1.414\end{array}$ & $\begin{array}{r}4.3 \\
74 \\
\\
3.9 \\
77\end{array}$ & 3.057 \\
\hline
\end{tabular}


Tabela 2. Caracterização geotécnica dos solos representativos das áreas monitoradas.

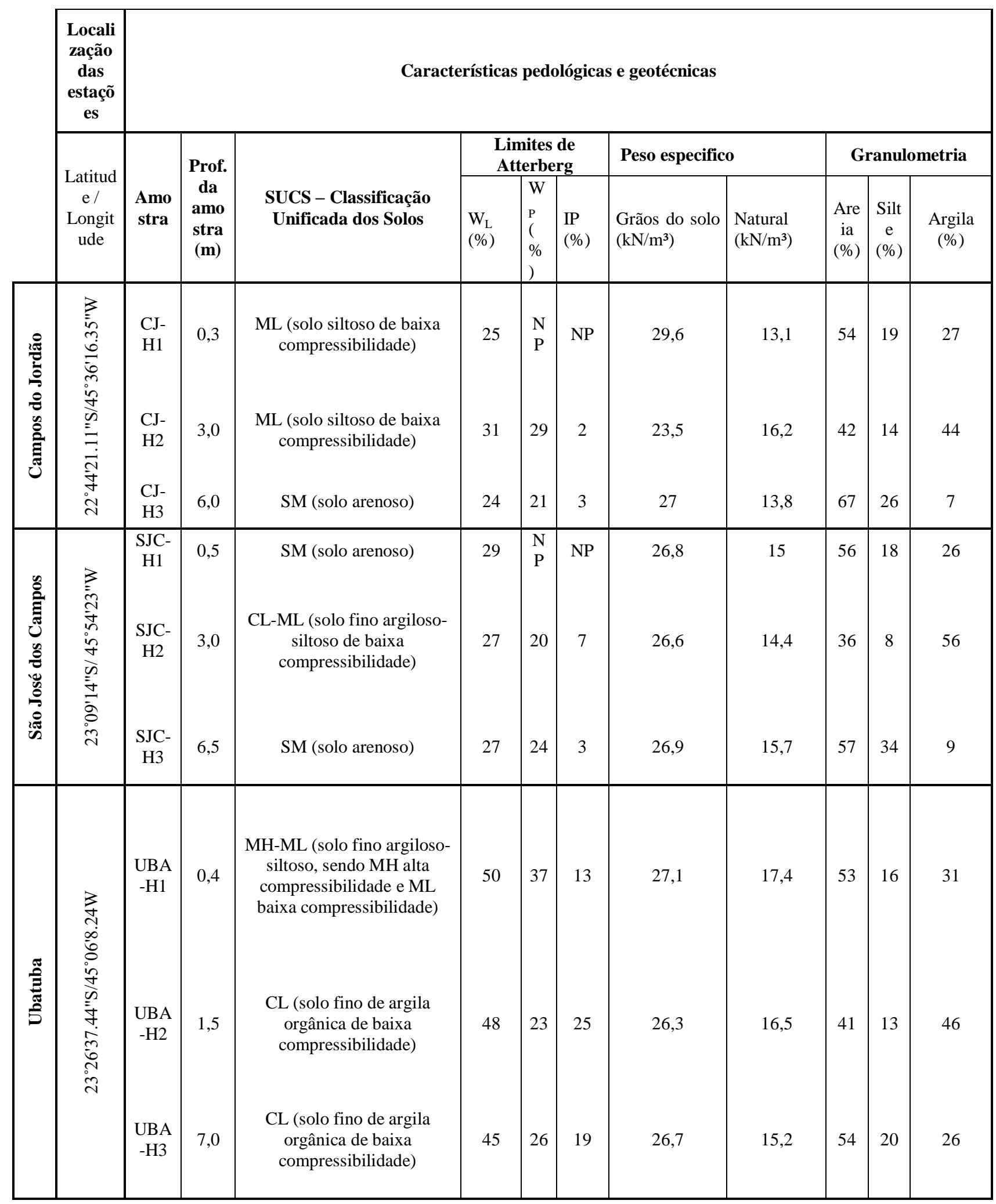

\subsection{Características dos deslizamentos nas áreas monitoradas}

A principal causa do processo de instabilização das encostas é a infiltração de água das chuvas nos terrenos (Wolle e Carvalho, 1989). Sendo esse o tipo de processo de instabilização predominante, nota-se que o monitoramento contínuo das variáveis associadas ao processo de infiltração e retenção de água no solo (chuva e teor de umidade do solo) é imprescindível para o melhor entendimento da função de cada variável no processo de instabilização das encostas urbanas. 
Em termos gerais, as principais condicionantes naturais responsáveis pela ocorrência dos deslizamentos nas encostas são: alta declividade (geralmente maiores que $30^{\circ}$ ) associada com sua morfologia (geometria côncava e/ou retilínea), presença de solo na condição não saturada e alta pluviosidade (acumulado e/ou intensidade horária de chuva). Adicionalmente, as ações humanas, tais como a execução de taludes de corte com altura/inclinação excessiva, aterro lançado com lixo e entulho, sobrecargas nos terrenos devido à construção de moradias com vários pavimentos, lançamentos de águas servidas, vazamentos de tubulações, aumenta significativamente as condições de instabilidade das encostas no ambiente urbano (MENDES et al., 2017, MENDES et al., 2018, KÖNIG et al., 2019).

Nas áreas de risco monitoradas tem-se observado a ocorrência predominante de deslizamentos superficiais (profundidade de ruptura menor que 2,0 metros), onde ocorreram alguns tipos preferenciais de ruptura das encostas e taludes, segundo observado por Mendes e Valério Filho (2015): tipo (A) - a ruptura ocorre na camada de solo "H1" da encosta; tipo (B) - a ruptura ocorre na camada de solo "H1" ou "H2" do talude de corte; tipo (C) - a ruptura ocorre na base do aterro lançado ou na camada de solo "H1" da encosta (com mobilização do aterro lançado sobrejacente), conforme apresentado na Figura 5.

Geralmente a ruptura do tipo (C) mobiliza maior quantidade de material e, consequentemente, tende a atingir um número maior de moradias e causar danos de maior gravidade. Em termos gerais, os autores observaram que as ações humanas interferem sobremaneira na deflagração dos deslizamentos nas áreas de risco estudadas, principalmente nos taludes de corte e aterro lançado, no que se refere à quantidade de chuva necessária para promover os deslizamentos. Por exemplo, os vazamentos em tubulações e caixas d'água existentes em encostas urbanas densamente ocupadas tendem a diminuir significativamente a quantidade de chuva necessária para a deflagração dos deslizamentos, pois promovem o aumento prévio e significativo da umidade do solo (MENDES; VALÉRIO FILHO, 2015). Contudo, a dificuldade técnica para coletar amostras indeformadas de solos envolvendo depósitos de encostas com lixo/entulho e consequentemente realizar ensaios laboratoriais para determinação de suas propriedades hidráulicas (curvas de retenção de água, por exemplo), inviabilizou a instalação dos sensores de umidade do solo nesse tipo de material.

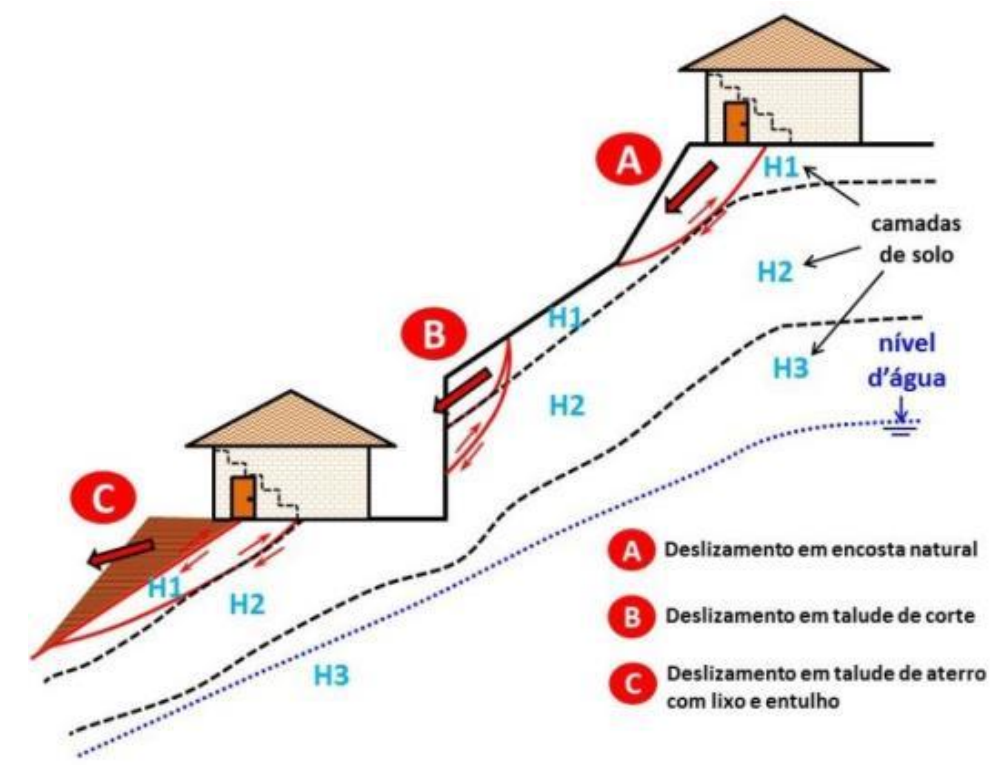

Figura 5: Principais tipos de ruptura em encostas urbanas (fonte: Mendes e Valério Filho, 2015).

Na Figura 6 são apresentados os locais de instalação do sistema de monitoramento e os pontos de deslizamentos ocorridos nos municípios de Campos do Jordão, São José dos Campos e Ubatuba no mês de janeiro de 2013. Nota-se nessa figura que as distâncias dos locais de instalação do sistema de monitoramento de chuva e umidade do solo aos pontos de deslizamentos variam de 400 metros (São José dos Campos) até 25,0 quilômetros (Ubatuba). Contudo, observa-se que a maioria das ocorrências de deslizamentos (total de 09 deslizamentos) está entre 400 metros a 3,5 quilômetros de distância dos locais de monitoramento. 


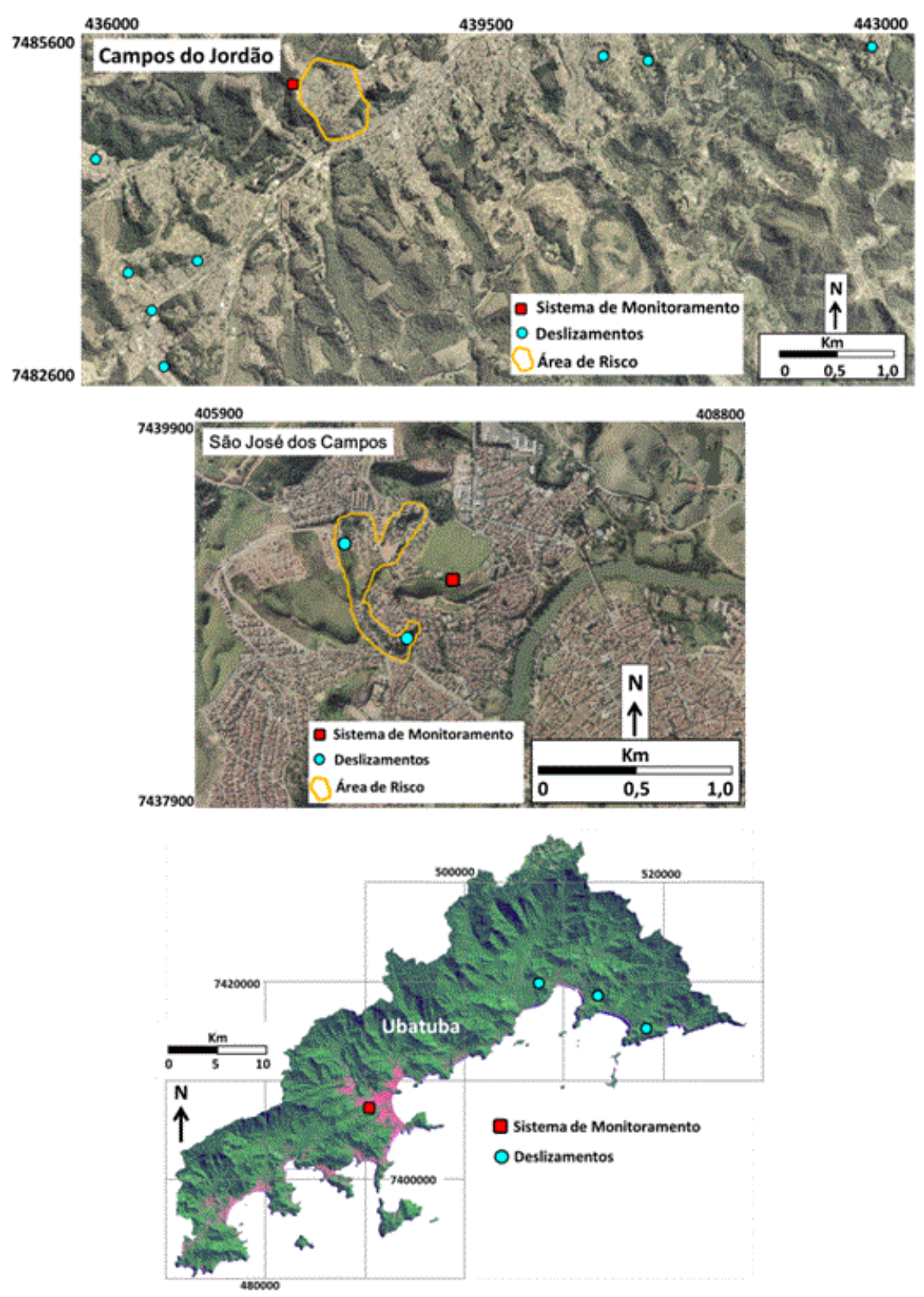

Figura 6: Locais de instalação do sistema de monitoramento e dos deslizamentos ocorridos em Campos do Jordão, São José dos Campos e Ubatuba.

\subsection{Procedimentos de instalação dos sensores ambientais}

Os sensores de monitoramento in situ foram instalados em terrenos situados nas imediações de áreas de risco nos municípios de Campos do Jordão, São José dos Campos e Ubatuba, conforme apresentado na Figura 3. Para a instalação dos sensores e demais equipamentos que compõem o "Sistema de Monitoramento", seguiram-se as recomendações de instalação do fabricante. A seguir são apresentados, resumidamente, os procedimentos adotados para a instalação dos sensores e demais equipamentos do sistema de monitoramento, conforme apresentado na Figura 7.

- Sensor de umidade do solo (Figuras 7a/7b) inicialmente foram feitos furos com trado até as profundidades desejadas de instalação dos sensores (entre 0,3 e 3,0 metros) e, em seguida cada sensor foi inserido diretamente no interior do furo até sua base com auxílio do "sistema de instalação" desenvolvido especialmente para este projeto;

- Sensor de chuva (pluviômetro) e sistema automático de aquisição e envio de dados (Figuras 7c/7d/7e/7f): tanto o medidor de chuva quanto o sistema automático de aquisição e envio de dados foram instalados diretamente em duas hastes de PVC rígido e, posteriormente, os cabos dos sensores de chuva e umidade do solo foram conectados diretamente ao sistema de aquisição de dados (datalogger).

Os registros dos dados de chuva e umidade do solo foram realizados em intervalos de 10 minutos; enquanto que o envio automático dos dados armazenados no sistema de aquisição (datalogger) foi feito em intervalos pré-programados de 4 horas, portanto, 06 (seis) vezes por dia. Durante o período de 
monitoramento dos dados climáticos e geotécnicos nos três municípios houve a ocorrência de alguns deslizamentos registrados no âmbito do Plano Preventivo de Defesa Civil, conforme apresentado por Mendes e Valério Filho (2015). A seguir, os dados do sistema de monitoramento são analisados conjuntamente com as informações dos registros de deslizamentos a fim de estabelecer limiares críticos de chuva e umidade do solo, para serem utilizados posteriormente em "Sistemas de Alertas a Deslizamentos".
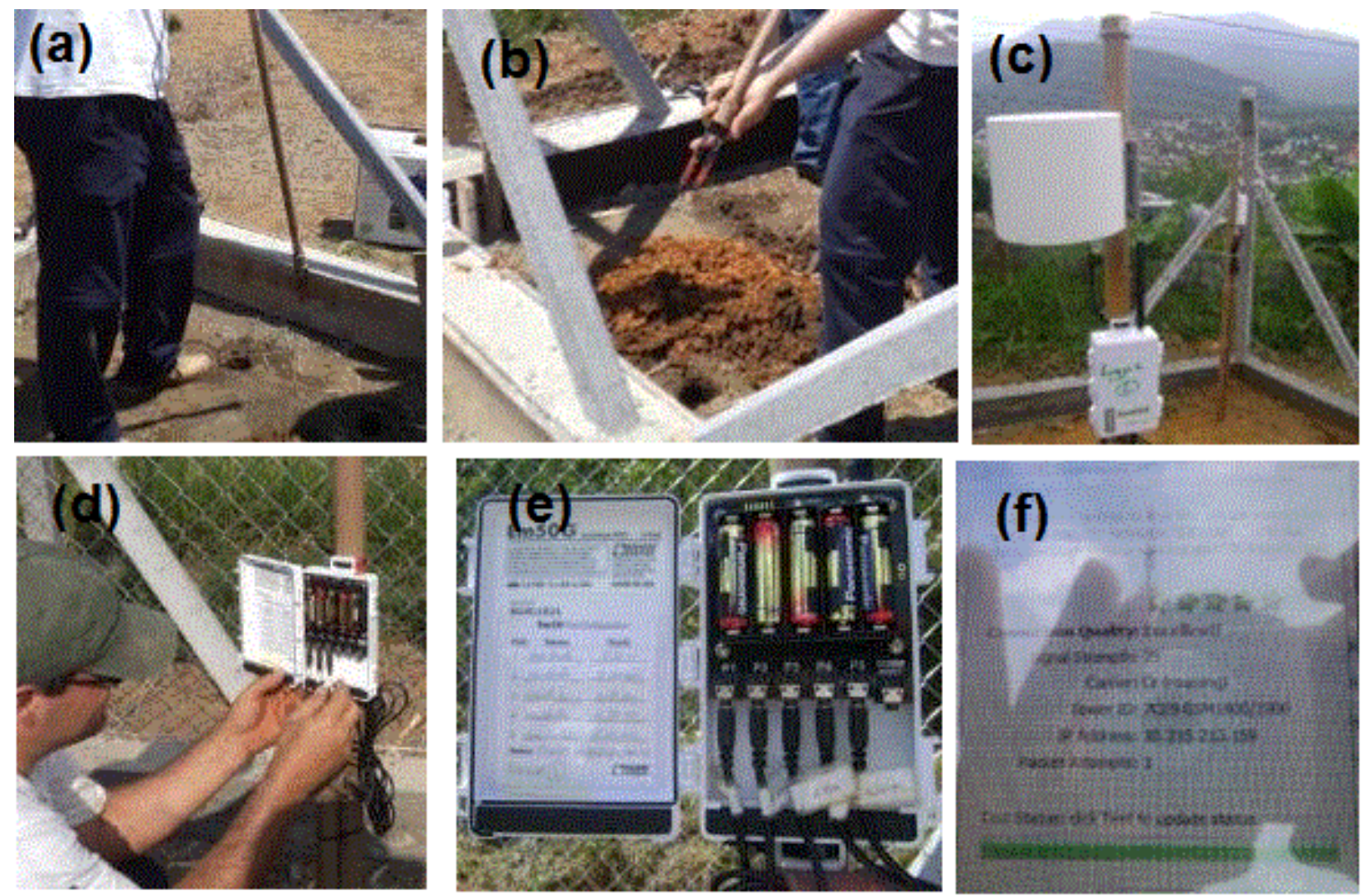

Figura 7: Instalação dos sensores de monitoramento in situ: (a) e (b) - sensor de umidade do solo; (c) sensor de chuva - pluviômetro de báscula; (d) e (e) - instalação do sistema de armazenamento e transmissão automática de dados (datalogger); (f) - teste de conexão do sistema de transmissão de dados (datalogger).

\section{Resultados e discussões}

Nas Figuras 8, 9 e 10 são apresentados os dados registrados pelo sistema de monitoramento nos três municípios analisados. Na parte superior dessas figuras são apresentados os dados de chuva e umidade do solo registrados no período de 06 (seis) meses, bem como indicadas (setas pretas) as datas de início dos deslizamentos (CEDEC, 2013): Campos do Jordão - 08 deslizamentos, com início no dia 11/01/2013; São José dos Campos - 02 deslizamentos, com início no dia 10/01/2013; Ubatuba - 03 deslizamentos, com início no dia 03/01/2013. Na parte inferior das Figuras 8, 9 e 10 são apresentados em detalhe os dados de chuva e umidade do solo para o período de ocorrência dos deslizamentos nos 03 municípios estudados.

Ao analisar conjuntamente os dados de chuva e umidade do solo das Figuras 8, 9 e 10, nota-se haver períodos críticos (zonas vermelhas destacadas nos gráficos) nos quais foram registradas ocorrências de deslizamentos nos três municípios. Em todos esses períodos críticos verificam-se índices elevados de chuva (intensidades e acumulados) e aumento significativo da umidade do solo ao longo dos perfis de solo monitorados.

Os valores máximos de intensidade da chuva registrados no período crítico foram de $43,8 \mathrm{~mm} / \mathrm{h}$ em Campos do Jordão; $56,0 \mathrm{~mm} / \mathrm{h}$ em São José dos Campos e $39,6 \mathrm{~mm} / \mathrm{h}$ em Ubatuba. Já os principais acumulados de chuva registrados no mesmo período crítico foram de $51,8 \mathrm{~mm} / 24 \mathrm{~h}$ e $62,4 / 72 \mathrm{~h}$ em Campos do Jordão; 89,4mm/24h e 90,8mm/72h em São José dos Campos; 84,8mm/24h e 133,0mm/72h em Ubatuba.

Os valores máximos de umidade do solo registrados nos perfis de solo durante o período crítico foram: i) para o sítio de Campos do Jordão (Figura 8) - sensor 0,3m (41\%); sensor 0,6m (43,5\%); sensor 1,0m (48\%); sensor 1,5m (45,5\%); sensor 2,0m (46\%); ii) para o sítio de São José dos Campos (Figura 9) - sensor 0,3m 
(43\%); sensor 0,6m (38,5\%); sensor 1,0m (43\%); sensor 2,0m (33,5\%); sensor 3,0m (27,5\%); para o sítio de Ubatuba (Figura 10) - sensor 0,3m (44,5\%); sensor 0,6m (46\%); sensor 1,0m (45,5\%); sensor 2,0m (45\%); sensor 3,0m (45\%). Observa-se que a maioria dos valores máximos de umidade do solo, registrados no período crítico (durante a ocorrência dos deslizamentos), está próxima do valor correspondente à saturação do solo, conforme indicado pelos valores de umidade saturada do solo apresentados na Figura 4 (valor de umidade do solo para sucção de 0,01 kPa: Campos do Jordão - CJ - 46 a 60\%; São José dos Campos - SJC - 44 a 55\%; Ubatuba - UBA - 38 a $49 \%$ ).
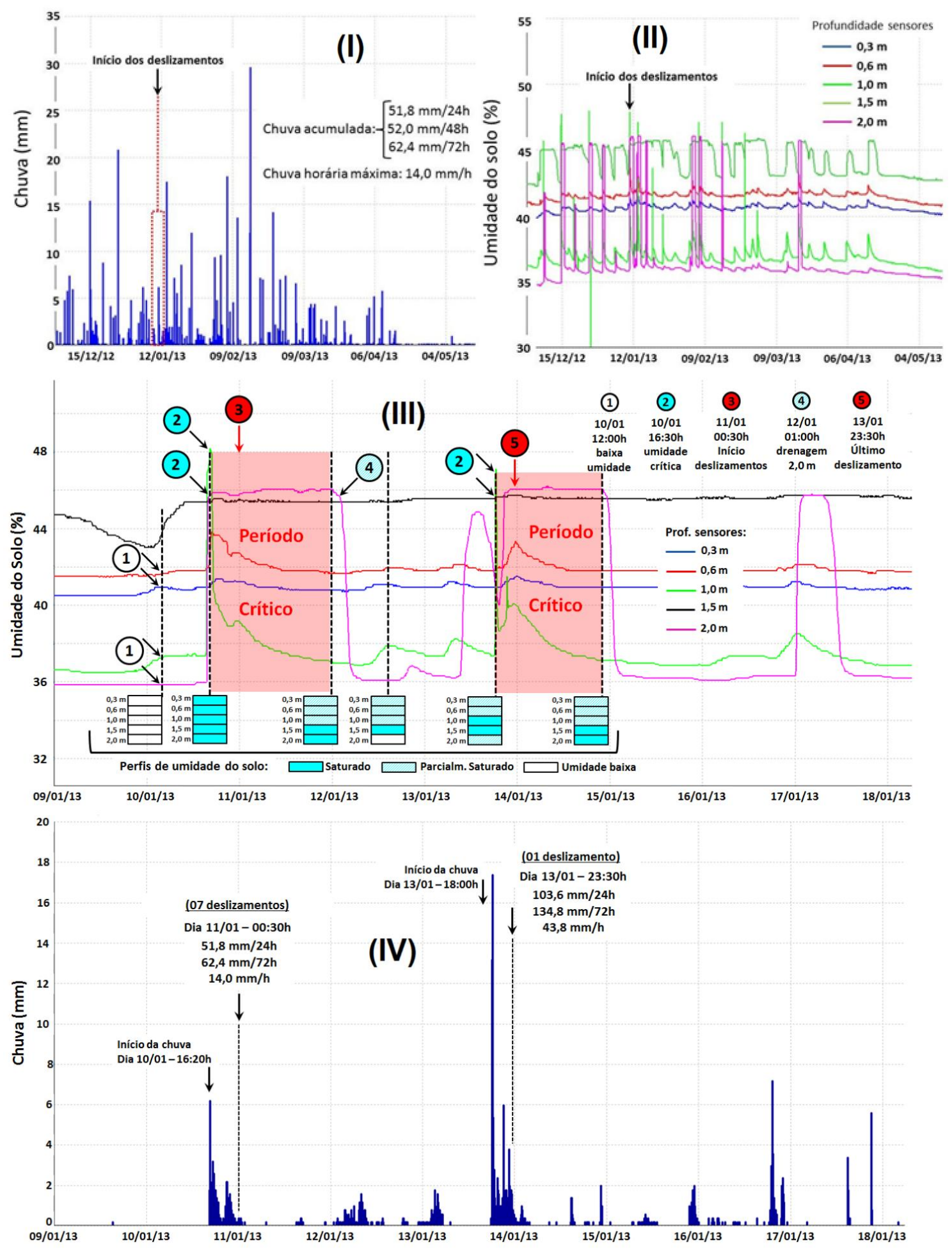

Figura 8: Dados de monitoramento dos sensores instalados em Campos do Jordão: (I, II) dados de chuva e umidade do solo para todo o período de monitoramento com indicação do início dos deslizamentos; (III) detalhe dos dados de umidade do solo para o período crítico com registros de deslizamentos; (IV) detalhe dos parâmetros de chuva para o período crítico com registros de deslizamentos. 

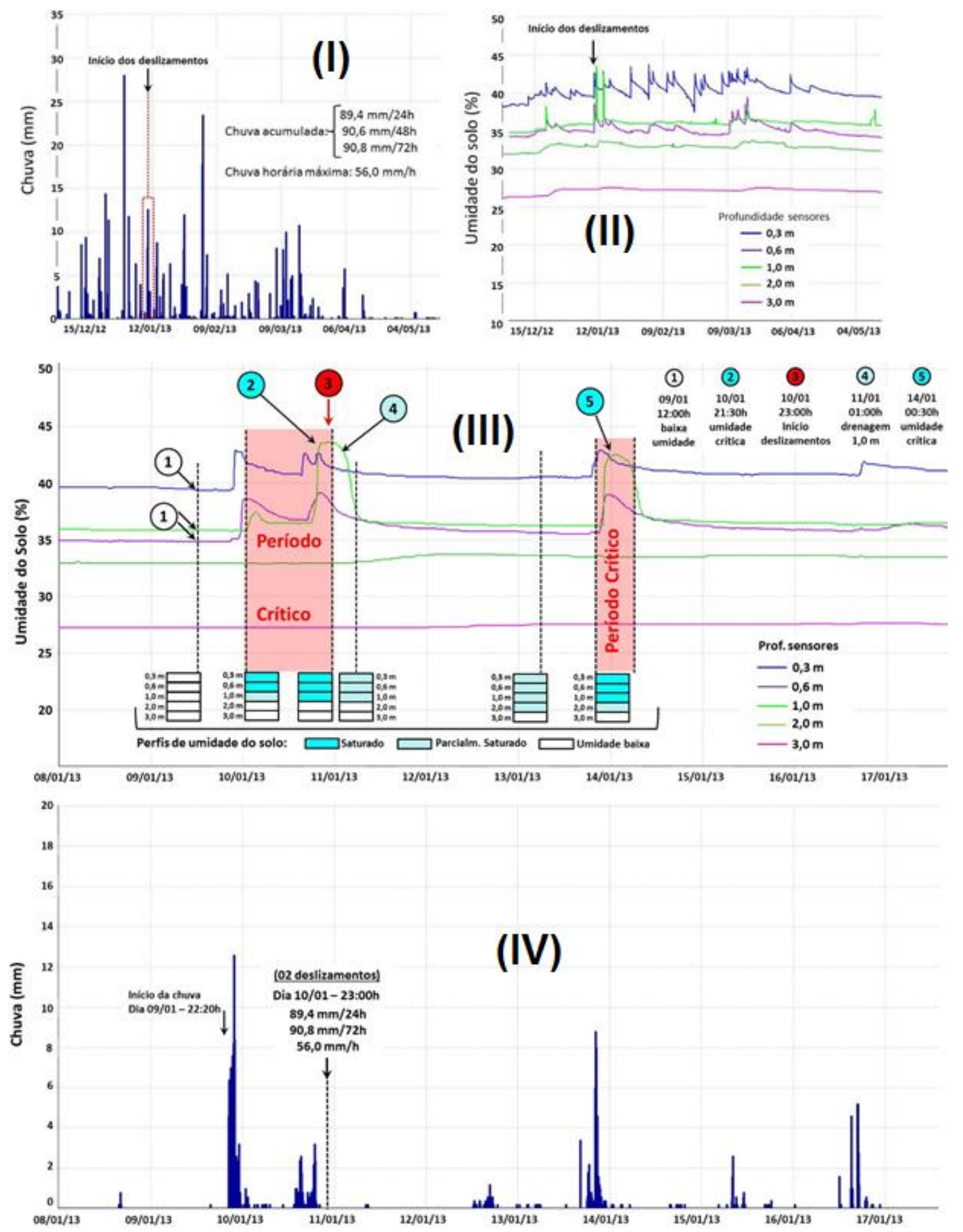

Figura 9: Dados de monitoramento dos sensores instalados em São José dos Campos: (I, II) dados de chuva e umidade do solo para todo o período de monitoramento com indicação do início dos deslizamentos; (III) detalhe dos dados de umidade do solo para o período crítico com registros de deslizamentos; (IV) detalhe dos parâmetros de chuva para o período crítico com registros de deslizamentos.

A partir da análise dos dados de umidade do solo registrados nos três municípios, constatou-se existir valores críticos de umidade ao longo das camadas de solo para os quais os deslizamentos são deflagrados (zonas vermelhas destacadas). Assim, as "Zonas Vermelhas" destacadas nas Figuras 8, 9 e 10 indicam o período de maior probabilidade de ocorrência de deslizamentos, pois as camadas de solo mais profundas encontram-se saturadas ou próximas da saturação. Adicionalmente, observa-se que, para a efetiva deflagração dos deslizamentos, o aumento de umidade deve ser mais expressivo nas camadas de solo mais profundas, ou seja, próximas à zona de ruptura da encosta ou talude (geralmente entre 1,0 a 2,0 metros). 
Analisando os dados de precipitação de Campo do Jordão (Figura 8), nota-se que as chuvas acumuladas de $24 \mathrm{~h}$ e $72 \mathrm{~h}$ desempenharam um papel mais importante para promover o aumento significativo de umidade do solo durante o período de ocorrência dos 07 (sete) primeiros eventos de deslizamento. Em relação aos dados de precipitação de São José dos Campos e Ubatuba (Figuras 9 e 10), verifica-se que tanto as chuvas acumuladas de $24 \mathrm{~h}$ e $72 \mathrm{~h}$ quanto a intensidade da chuva podem ter contribuído significativamente para a deflagração dos eventos de deslizamento. Contudo, deve-se ressaltar que os dados de monitoramento de Ubatuba devem ser analisados com ressalvas, devido principalmente à considerável distância entre o local de implantação do sistema de monitoramento e os locais de ocorrências dos deslizamentos.
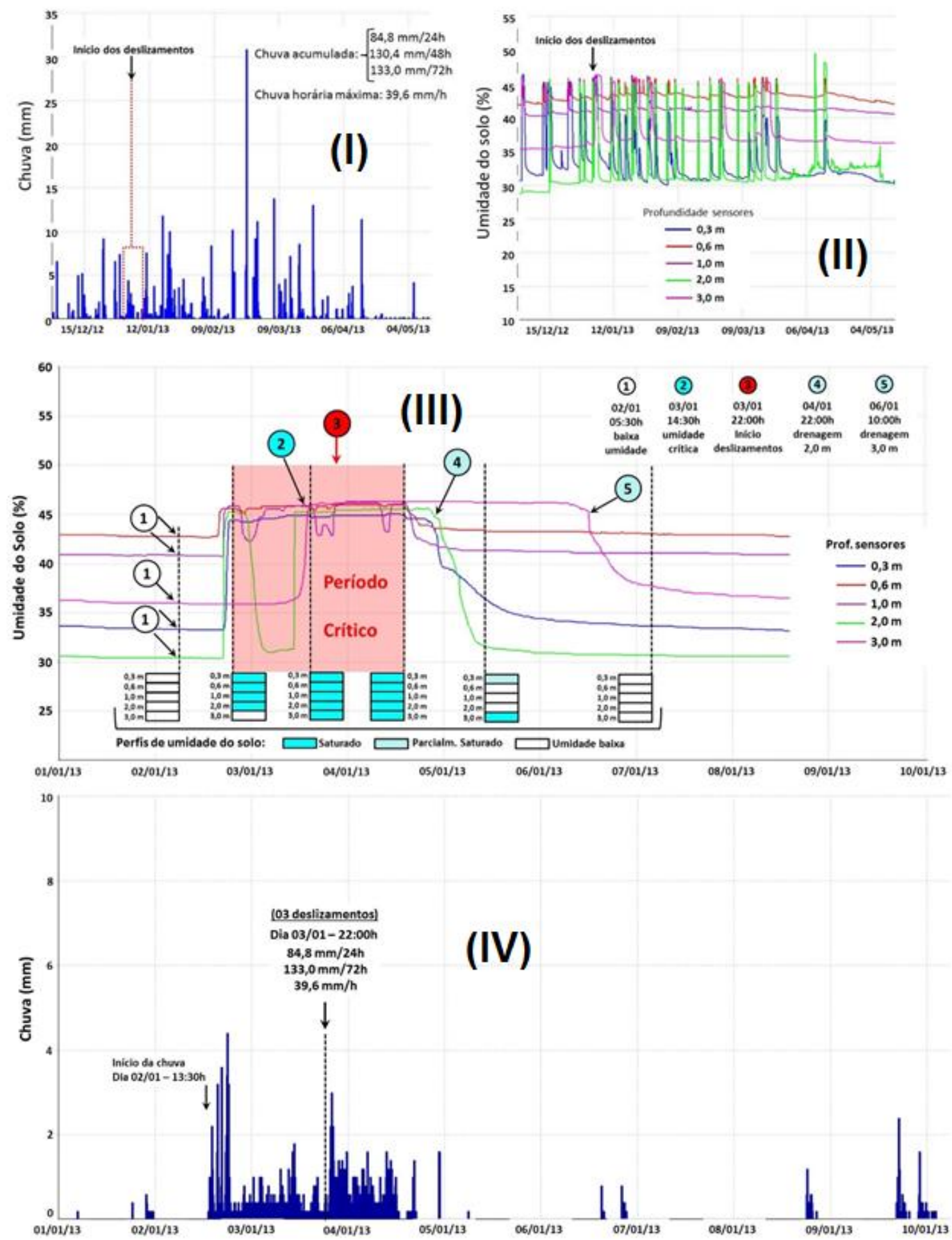

Figura 10: Dados de monitoramento dos sensores instalados em Ubatuba: (I, II) dados de chuva e umidade do solo para todo o período de monitoramento com indicação do início dos deslizamentos; (III) detalhe dos dados de umidade do solo para o período crítico com registros de deslizamentos; (IV) detalhe dos parâmetros de chuva para o período crítico com registros de deslizamentos. 
Considerando a tipologia principal dos deslizamentos que ocorreram nos municípios de Campos do Jordão, São José dos Campos e Ubatuba (total de 13 deslizamentos), ou seja, deslizamentos em encostas urbanas com presença de fatores indutores antrópicos (taludes de corte/aterro com ou sem lixo/entulho, existência de vazamentos pontuais, sobrecargas em terrenos, etc.), conforme descrito por Mendes e Valério Filho (2015), bem como os dados de monitoramento registrados nos três municípios durante os deslizamentos, é possível sugerir alguns limiares críticos ambientais para as áreas de risco dos três municípios monitorados, conforme apresentado na Tabela 3.

Tabela 3: Limiares críticos ambientais sugeridos para uso em sistema de monitoramento e alertas antecipados a deslizamentos nas áreas estudadas

\begin{tabular}{|c|c|c|c|c|c|c|c|c|c|c|}
\hline \multirow{2}{*}{$\begin{array}{c}\text { NÍVEL } \\
\text { OPERACIONAL }\end{array}$} & \multirow[b]{2}{*}{ MUNICÍPIO } & \multicolumn{3}{|c|}{ PARÂMETROS DE CHUVA } & \multicolumn{6}{|c|}{ ATINGIMENTO DA UMIDADE CRÍTICA NO PERFIL DE SOLO } \\
\hline & & $(\mathrm{mm} / \mathrm{h})$ & $(\mathrm{mm} / 24 \mathrm{~h})$ & $(\mathrm{mm} / 72 \mathrm{~h})$ & $\begin{array}{l}\text { Prof. } \\
(0,3 \mathrm{~m})\end{array}$ & $\begin{array}{l}\text { Prof. } \\
(0,6 \mathrm{~m})\end{array}$ & $\begin{array}{l}\text { Prof. } \\
(1,0 \mathrm{~m})\end{array}$ & $\begin{array}{l}\text { Prof. } \\
(1,5 \mathrm{~m})\end{array}$ & $\begin{array}{l}\text { Prof. } \\
(2,0 \mathrm{~m})\end{array}$ & $\begin{array}{l}\text { Prof. } \\
(3,0 \mathrm{~m})\end{array}$ \\
\hline \multirow{6}{*}{ OBSERVAÇÃO } & Campos do Jordão & \\
\hline & & \multicolumn{9}{|c|}{ Condições para retornar ao nível "Observação": } \\
\hline & São José dos Campos & \multirow{3}{*}{\multicolumn{9}{|c|}{$\begin{array}{l}\text { 1a) cessar chuvas; } \\
\text { 2a) sem previsão de chuvas nas próximas } 48 \text { horas e } \\
\text { 3a) umidade baixa (drenagem) das camadas mais profundas }(1,5 \text { a 3,0m). }\end{array}$}} \\
\hline & 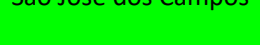 & & & & & & & & & \\
\hline & & & & & & & & & & \\
\hline & Ubatuba & & & & & & & & & \\
\hline \multirow{3}{*}{ ATENÇÃO } & Campos do Jordão & $\geq 30$ & $\geq 50$ & $\geq 60$ & SIM & SIM & SIM & SIM & NÃO & - \\
\hline & São José dos Campos & $\geq 50$ & $\geq 70$ & $\geq 80$ & SIM & SIM & SIM & - & NÃO & SIM \\
\hline & Ubatuba & $\geq 40$ & $\geq 80$ & $\geq 100$ & SIM & SIM & SIM & - & NÃO & SIM \\
\hline \multirow{3}{*}{ ALERTA } & Campos do Jordão & $\geq 45$ & $\geq 80$ & $\geq 100$ & SIM & SIM & SIM & SIM & SIM & - \\
\hline & São José dos Campos & $\geq 60$ & $\geq 90$ & $\geq 120$ & SIM & SIM & SIM & - & SIM & SIM \\
\hline & Ubatuba & $\geq 60$ & $\geq 100$ & $\geq 130$ & SIM & SIM & SIM & - & SIM & SIM \\
\hline
\end{tabular}

Nota: no caso do retorno do nível de "ALERTA" para "OBSERVAÇÂO" também deverá ser avaliado o atendimento às recomendações técnicas eventualmente indicadas nos relatórios dos atendimentos emergenciais.

A grande vantagem do uso conjunto destes limiares críticos é a possibilidade de utilizá-los para ingressar aos níveis operacionais mais críticos (de "OBSERVAÇÃO" para "ATENÇÃO ou ALERTA") ou para retornar ao nível operacional menos crítico (de "ATENÇÃO ou ALERTA" para "OBSERVAÇÃO") sem a necessidade de vistoriar as áreas de risco in loco, quando atingidos simultaneamente os limiares críticos de chuva e umidade do solo para a primeira situação; ou quando atendidas as 03 (três) condições sugeridas na Tabela 3 para o segundo caso. A adoção de mais um parâmetro ambiental, como a umidade do solo, seja como critério de ingresso aos níveis operacionais mais críticos (ATENÇÃO e ALERTA) ou de retorno ao nível operacional menos crítico (OBSERVAÇÃO), tende a melhorar significativamente a precisão dos alertas emitidos, pois a maior ou menor probabilidade de deflagração dos deslizamentos depende fundamentalmente, além da chuva, da quantidade de água armazenada ou drenada do perfil de solo. Logo, o uso de parâmetros alternativos e complementares, tais como a umidade do solo permitirá o aperfeiçoamento de sistemas de alertas antecipados a deslizamentos baseados apenas em limiares críticos de precipitação.

\section{Conclusões}

Primeiramente, constatou-se que as principais variáveis ambientais responsáveis pela deflagração dos deslizamentos ocorridos nas áreas estudadas foram: o aumento significativo da umidade do solo a partir de 1,0 até 3,0 metros de profundidade; a intensidade da chuva horária e chuvas acumuladas de $24 \mathrm{~h}$ e $72 \mathrm{~h}$. Verificou-se existir valores críticos de umidade do solo ao longo dos perfis do solo para os quais os deslizamentos são deflagrados. Para os três perfis de solos monitorados, os valores críticos de umidade do solo estão situados entre $38,5 \%$ a $46 \%$, ou seja, valores próximos da saturação do solo, a depender da profundidade de instalação do sensor. Além disso, observou-se que, para a efetiva deflagração dos escorregamentos, o aumento de umidade do solo deve ser mais expressivo nos horizontes/camadas de solo mais profundas (geralmente entre 1,0 a 3,0 metros). 
A partir da análise dos dados de precipitação, verificou-se haver uma relação inversamente proporcional entre o nível de intervenção humana nas áreas de risco e a quantidade de chuva necessária para a deflagração dos deslizamentos nas áreas monitoradas, ou seja, quanto maior for o nível de intervenção humana (corte/aterro, lançamento de água servida, vazamentos, etc.), menor será a quantidade de chuva necessária para a deflagração dos deslizamentos. Constatou-se também que o monitoramento da intensidade da chuva horária e da chuva acumulada de 24 horas é imprescindível para a previsão dos deslizamentos em áreas de risco, principalmente quando estas forem densamente ocupadas.

As análises dos dados de monitoramento obtidos permitiram constatar que a consideração de limiares ambientais complementares, tais como a umidade do solo, em associação com índices pluviométricos, podem proporcionar alertas mais precisos nos municípios estudados. O monitoramento em tempo real e simultâneo da chuva e umidade do solo mostrou ser imprescindível para o melhor entendimento do processo de deflagração dos deslizamentos em áreas de risco, bem como revelou ser promissor para o estabelecimento de limiares ambientais críticos para uso em sistema de alertas antecipados a deslizamentos.

Em virtude da maioria dos deslizamentos registrados no presente estudo envolverem materiais de depósito de encosta (lixo/entulho), taludes de corte, sobrecargas nos terrenos, lançamentos de águas servidas e vazamentos de tubulações; ressalta-se a necessidade do desenvolvimento de estudos complementares com a finalidade de analisar pontualmente a influência desses condicionantes antrópicos na deflagração dos deslizamentos e, consequentemente, nos valores dos limiares críticos ambientais utilizados em sistemas de alertas.

\section{Agradecimentos}

Os autores agradecem à Fundação de Amparo à Pesquisa do Estado de São Paulo (FAPESP) pela concessão de auxílio à pesquisa (Processo $\left.n^{\circ} 11 / 22577-2\right)$.

\section{Referências}

AHRENDT, A.; ZUQUETTE, L.V.; Triggering factors of landslides in Campos do Jordão city, Brazil, Bulletin of Engineering Geology and the Environment.v.62, 231-244, 2003. DOI: 10.1007/s10064-0030191-8

ANGELI, M.G.; PASUTO, A.; SILVANO, S.A.; Critical review of landslide monitoring experiences. Engineering Geology. v.55, 133-147, 2000. DOI: 10.1016/S0013-7952(99)00122-2

ASSOCIAÇÃO BRASILEIRA DE NORMAS TÉCNICAS (ABNT). Grãos de solo que passam na peneira de 4,8mm - Determinação da massa específica, NBR-6508. Rio de Janeiro, 8p, 1984.

ASSOCIAÇÃO BRASILEIRA DE NORMAS TÉCNICAS (ABNT). Solo - Análise granulométrica, NBR7181. Rio de Janeiro, 13p, 1984.

ASSOCIAÇÃO BRASILEIRA DE NORMAS TÉCNICAS (ABNT). Solo - Determinação do limite de liquidez, NBR 6459. Rio de Janeiro, 6p, 1984.

ASSOCIAÇÃO BRASILEIRA DE NORMAS TÉCNICAS (ABNT). Solo - Determinação do limite de plasticidade, NBR 7180. Rio de Janeiro, 3p, 1984.

BROLLO, M.J., TOMINAGA, L.K. Desastres naturais e riscos geológicos no estado de São Paulo: cenário de referência - 2012. São Paulo: Coordenadoria Estadual de Defesa Civil; 2012.

CEDEC-COORDENADORIA ESTADUAL DE DEFESA CIVIL. Notícias e Operação Verão, 2013. Disponível em: <http://www.defesacivil.sp.gov.br/v2010/portal_defesacivil/index.asp>.

CHAVÉZ, J.A.; LANDAVERDE, J.; LANDAVERDE, R.L.; TEJNECKY, V.; Monitoring and behavior of unsaturated volcanic pyroclastic in the Metropolitan Area of San Salvador, El Salvador. SpringerPlus. 5:536, 2016, DOI: 10.1186/s40064-016-2149-x 
FISCH, G.; VENDRAME, I.F.; HANAOKA, P.C.M.; Variabilidade espacial da chuva durante o experimento LBA/TRMM 1999 na Amazônia. Acta Amazonica. v.37, 583-590, 2007. DOI: 10.1590/S004459672007000400013

IG-INSTITUTO GEOLÓGICO. Mapeamento de riscos associados a escorregamentos, inundações, erosão e solapamento de margens de drenagens - município de Campos do Jordão, 2014. Disponível em: $<$ http://www.defesacivil.sp.gov.br/instrumentos-de-identificacao-de-riscos/>.

KÖNIG, T.; KUX, H.J.H.; MENDES, R.M.; Shalstab mathematical model and WorldView-2 satellite images to identification of landslide-susceptible areas. Natural Hazards. v.97, 1127-1149, 2019. DOI: 10.1007/s11069-019-03691-4

LEUNG, A.K.; SUN, H.W.; MILLIS, S.W.; PAPPIN, J.W.; NG, C.W.W.; WONG, H.N.; Field monitoring of an unsaturated saprolitic hillslope. Canadian Geotechnical Journal. v.48, 339-353, 2011. DOI: $10.1139 / \mathrm{T} 10-069$

LI, A.G.; YUE, Z.Q.; THAM, L.G.; LEE, C.F.; LAW, K.T.; Field-monitored variations of soil moisture and matric suction in a saprolite slope. Canadian Geotechnical Journal. v.42, 13-26, 2005. DOI: 10.1139/t04069

MENDES, R.M.; DE ANDRADE, M.R.M.; GRAMINHA, C.A.; PRIETO, C.C.; DE ÁVILA, F.F.; CAMARINHA, P.I.M.; Stability Analysis on Urban Slopes: Case Study of an Anthropogenic-Induced Landslide in São José dos Campos, Brazil. Geotechnical and Geological Engineering. v.36, 599-610, 2017. DOI: $10.1007 / \mathrm{s} 10706-017-0303-\mathrm{z}$

MENDES, R.M.; DE ANDRADE, M.R.M.; TOMASELLA, J.; DE MORAES, M.A.E.; SCOFIELD, G.B.; Understanding shallow landslides in Campos do Jordão municipality (Brazil): disentangling the anthropic effects from natural causes in the disaster of 2000. Natural Hazards and Earth System Sciences. v.18, 1530, 2018. DOI: $10.5194 /$ nhess-18-15-2018

MENDES, R.M.; VALERIO FILHO, M.; Real-Time monitoring of climactic and geotechnical variables during landslides on the slopes of Serra do Mar and Serra da Mantiqueira (Sao Paulo State, Brazil). Engineering. v.7, 140-159, 2015. DOI: 10.4236/eng.2015.73012

PIRONE, M.; PAPA, R.; NICOTERA, M.V.; URCIUOLI, G.; In situ monitoring of the groundwater field in an unsaturated pyroclastic slope for slope stability evaluation. Landslides. v.12, 259-276, 2015. DOI: 10.1007/s10346-014-0483-z

PMSJC - PREFEITURA MUNICIPAL DE SÃO JOSÉ DOS CAMPOS. Mapeamento das áreas de riscos associados a escorregamentos de encostas no município de São José dos Campos-SP, 2014. Disponível em: <http://planodiretor.sjc.sp.gov.br/resources/uploads/Link/Arquivo/2016_AreasRisco.pdf>.

SANTORO, J.; MENDES, R.M.; PRESSINOTTI, M.M.N.; MANOEL, G.R. Correlação entre chuvas e deslizamentos ocorridos durante a operação do Plano Preventivo de Defesa Civil em São Paulo, SP. In: SIMPÓSIO BRASILEIRO DE CARTOGRAFIA GEOTÉCNICA E GEOAMBIENTAL, 7.; 2010, Maringá. Anais... Maringá: ABGE, 2010. p. 1-15.

TATIZANA, C.; OGURA, A.T.; CERRI, L.E.S.; ROCHA, M.C.M. Análise da correlação entre chuvas e deslizamentos na Serra do Mar, município de Cubatão. In: CONGRESSO BRASILEIRO DE GEOLOGIA DE ENGENHARIA, 5.; 1987, São Paulo. Anais... São Paulo: ABGE, 1987. p. 225-236.

TOLL, D.G.; LOURENÇO, S.D.N.; MENDES, J.; GALLIPOLI, D.; EVANS, F.D.; AUGARDE, C.E.; CUI, Y.J.; TANG, A.M.; ROJAS, J.C.; PAGANO, L.; MANCUSO, C.; ZINGARIELLO, C.; TARANTINO, A.; Soil suction monitoring for landslides and slopes. Quarterly Journal of Engineering Geology and Hydrogeology. v.44, 23-33, 2010. DOI: 10.1144/1470-9236/09-010

VARGAS, M.; Revisão histórico-conceitual dos deslizamentos da Serra do Mar. Solos e Rochas: revista latino-americana de geotecnia, v.22, 53-83, 1999. 
WOLlE, C.M.; CARVALHO, C.S.; Deslizamentos em encostas na Serra do Mar (Brasil). Revista Solos e Rochas: revista latino-americana de geotecnia. v.12, 27-36, 1989.

ZHAN, T.L.T.; NG, C.W.W.; FREDLUND, D.G.; Field study of rainfall infiltration into a grassed unsaturated expansive soil slope. Canadian Geotechnical Journal. v.44, 392-408, 2007. DOI: $10.1139 / \mathrm{T} 07-001$

(1) (5) (2)

BY 